\title{
Multiple cytokine expression profiles reveal immune-based differences in occult hepatitis B genotype $\mathrm{H}$-infected Mexican Nahua patients
}

\author{
Nora Alma Fierro, Sonia Roman, Mauricio Realpe, Zamira Hernandez-Nazara, \\ Eloy Alfonso Zepeda-Carrillo, Arturo Panduro/ ${ }^{+}$
}

Servicio de Biologia Molecular en Medicina, Antiguo Hospital Civil de Guadalajara Fray Antonio Alcalde,

Centro Universitario de Ciencias de la Salud, Universidad de Guadalajara Hospital 278 Col. El Retiro, 44280 Guadalajara, Jalisco, México

A high prevalence of occult hepatitis $B(O H B)$ genotype $H$ infections has been observed in the native Mexican Nahua population. In addition, a low incidence of hepatitis B virus (HBV)-associated hepatocellular carcinoma has been described in Mexico. The immune response to infection among OHB-infected patients has been poorly evaluated in vivo. Therefore, we assessed the expression profiles of 23 cytokines in OHB genotype H-infected Nahua patients. A total of 41 sera samples from natives of the Nahua community were retrospectively analysed. Based on their HBV antibody profiles, patients were stratified into two groups: OHB patients $(n=21)$ and patients that had recovered from HBV infection $(n=20)$. Herein, we report distinctive cytokines profiles in OHB-infected individuals. Compared to healthy controls $(n=20)$ and patients who resolved HBV infection, OHB-infected patients displayed an increase in interleukin (IL)-2 secretion in addition to a characteristic inflammation profile (decrease in IL-8 and tumour necrosis factor-alpha levels and increased levels of tumour growth factor-beta). IL-15 and interferon-gamma levels were reduced in OHB-infected individuals when compared to those patients who resolved $H B V$ infection. In contrast, OHB patients showed an increase in monocyte chemoattractant protein (MCP)-1 and MCP-2 compared to healthy controls and patients who resolved HBV infection. These findings suggest that cytokine expression can influence the severity of $\mathrm{OHB}$ disease and could lead to new investigation into the treatment of liver and other infectious diseases.

Key words: hepatitis B virus - occult hepatitis B infection - cytokines - native Mexicans - HBV genotype-H

Hepatitis B infection is caused by the hepatitis B virus (HBV). This virus infects the liver and can lead to fibrosis, cirrhosis and hepatocellular carcinoma (HCC). Approximately one third of the world's population has been infected with HBV (Kurbanov et al. 2010). While chronic HBV infection is diagnosed by the presence of the hepatitis B surface antigen (HBsAg) and HBV DNA in patient serum, occult hepatitis B (OHB) is diagnosed by testing negative for $\mathrm{HBsAg}$ in serum, presence of $\mathrm{HBV}$ DNA in the liver and maintaining very low HBV DNA in the serum (Raimondo et al. 2008, 2010, Hollinger \& Sood 2010). OHB infection may be further stratified by HBV antibody profiles into seropositive and seronegative categories. Seronegative subjects are negative for both hepatitis B core antibody (anti-HBc) and hepatitis B surface antibody (anti-HBs), whereas seropositive individuals are positive for anti-HBc and can be either positive or negative for anti-HBs (Hollinger \& Sood 2010). OHB has been reported in patients with $\mathrm{HCC}$ and with chronic hepatitis $\mathrm{C}$ and co-infection with $\mathrm{OHB}$ and $\mathrm{HCV}$ is associated with more severe liver disease. In regions endemic for $\mathrm{HBV}$ infection, OHB is common and there is a

Financial support: CONACyT (CB-2009-127229) (to NAF), COECYTJAL-UdeG (to AP)

+Corresponding author: apanduro@prodigy.net.mx

Received 10 April 2011

Accepted 22 September 2011 rate of $17-19 \%$ of $\mathrm{HBV}$ infection as a result of liver transplantations from donors who were $\mathrm{HBsAg}$ negative (Prieto et al. 2009). OHB has also been found in healthy blood donors, indicating another potential route for the transmission of the disease (Candotti \& Allain 2009).

HBV genotypes (A-H) are heterogeneously distributed around the world. Genotypes B and C predominate in Asia (Osiowy et al. 2006) and genotype F is predominate in Latin America (Campos et al. 2005, Mbayed et al. 2009). Genotype $\mathrm{H}$ has been primarily detected in Mexico (Sanchez et al. 2002, 2007). We have shown previously that $\mathrm{OHB}$ genotype $\mathrm{H}$ is common among the ethnic Nahua population (Roman et al. 2010). Additionally, Mexico has been reported to be a low endemic area for HBV and there is a low association between HBV infection and HCC reported in the country (Roman et al. 2010). These data may indicate that the natural course of liver diseases in the native populations of Mexico may be different from what is described in high endemic areas for $\mathrm{HBV}$ infection. This suggests that the Nahua population is an invaluable resource to evaluate $\mathrm{OHB}$ infection.

Cytokines and receptors are both known to be key elements in liver disease progression (Akpolat et al. 2005, Frodsham et al. 2006). Additionally, it is accepted that liver damage is likely a result of the immune response to HBV infection (Racanelli \& Rehermann 2006, Corazza et al. 2009, Wang \& Zhang 2009). Thus, viral transcription repression, which results in both negative HBsAg and detectable levels HBV DNA in the serum, may be cytokine modulated. The immune mechanisms that modulate $\mathrm{OHB}$ are poorly understood in vivo. Therefore, we measured relative serum cytokines levels in 
OHB-infected Nahua natives to determine if cytokine expression levels distinguish OHB, genotype $\mathrm{H}$-infected patients as a result of a coordinated immune response.

\section{SUBJECTS, MATERIALS AND METHODS}

Subjects - A previous, cross-sectional study conducted by our group revealed that OHB genotype $\mathrm{H}$ infection is common among members of the Nahua community (Roman et al. 2010). In the present study, 41 sera samples from Nahua subjects were retrospectively analysed. Based on their molecular and HBV antibody profiles, patients were classified in two groups: $21 \mathrm{OHB}$, genotype $\mathrm{H}$-infected patients (HBsAg-, HBV DNA+, anti$\mathrm{HBc}+/-)$ and 20 Nahua patients who had recovered from HBV infection (HBsAg-, HBV DNA-, anti-HBc+). A total of 20 healthy Nahua donors (HBsAg-, HBVDNA-, anti-HBc-) were also studied. All patients were negative for antibodies to hepatitis $\mathrm{C}$ virus and human immunodeficiency virus (Roman et al. 2010).

Clinical history and demographical data were collected from all participants by a structured questionnaire as previously reported (Roman et al. 2010). Liver alanine aminotransferase (ALT) and aspartate aminotransferase (AST) levels were measured in patient serum by an enzymatic method (Human, Wiesbaden, Germany) in an automated analyser. Abnormal cut-off values for ALT and AST enzymes were $40 \mathrm{UI} / \mathrm{mL}$ and $50 \mathrm{UI} / \mathrm{mL}$, respectively (Roman et al. 2010). Individual liver enzymes levels were retrospectively analysed from the patient's medical records and grouped according to the categories described in the study (Table). There were no significant differences between the demographic variables (age/ gender) of the patient and control groups (Table).

Serology - All serum samples were screened previously for $\mathrm{HBsAg}$ and anti-HBc (total immunoglobulin $M$ and immunoglobulin $G$ ) with IMx CORE (Abbot

TABLE

Clinical characteristics of patients and controls

\begin{tabular}{lccc}
\hline & $\begin{array}{c}\text { Healthy } \\
\text { donors }\end{array}$ & OHB & Resolved HBV \\
\hline $\mathrm{N}$ & 20 & 21 & 20 \\
Female (\%) & 80 & 76 & 70 \\
Age (years) & $28.7 \pm 11.58$ & $27.81 \pm 8.02$ & $28.25 \pm 10.96$ \\
Median ALT & $24.8 \pm 14.85$ & $40.91 \pm 22.05$ & $32.85 \pm 16.01$ \\
(IU/L \pm SD) & & & \\
Median AST & $25.25 \pm 8.71$ & $32.61 \pm 12.04$ & $28.05 \pm 8.01$ \\
(IU/L \pm SD) & & - & - \\
HBsAg status & - & +- & + \\
Anti-HBc status & - & + & - \\
HBVDNA & - & &
\end{tabular}

ALT: alanine aminotransferase; anti-HBc: hepatitis B core antibody; AST: aspartate aminotransferase; HBsAg: hepatitis B surface antigen; HBV: hepatitis B virus; IU: international units; OHB: occult hepatitis B; SD: standard deviation.
Laboratories, Chicago, IL, USA) microparticle enzyme immunoassays on an IMx analyser according to the manufacturer's guidelines (Roman et al. 2010). These data were retrospectively analysed and grouped according to the categories described in this study (Table).

$O H B$ diagnosis - Assays of the highest sensitivity and specificity must be used for OHB diagnosis. The optimal, standard analysis methods for HBV DNA extracted from plasma samples are nested polymerase chain reaction (PCR) and sequencing. To avoid false-negative and false-positive results, designed PCR primers should span at least three genomic regions of the HBV genome (Raimondo et al. 2010). Therefore, nested PCR primers were used to amplify and detect the $\mathrm{S}$ and $\mathrm{C}$ regions in purified viral DNA from patient serum (Sanchez et al. 2002). Amplification of the core region of HBV was performed as described previously (Torres-Baranda et al. 2006). HBV DNA samples that were determined to be positive were further tested with genotype $\mathrm{H}$-specific primers (Roman et al. 2010).

Cytokine production - A dot blot-based assay was used according to the manufacturer's instructions (Ray-Biotech, Norcross, GA, USA) to detect relative expression levels of pro-inflammatory cytokines [interleukin (IL)-8, tumour necrosis factor-alpha (TNF- $\alpha$ ), IL-2, IL-1 and IL-6], anti-inflammatory cytokines [IL13, tumour growth factor-beta (TGF- $\beta$ ) and IL-10], immunoregulatory cytokines [IL-5, IL-15, interferongamma (IFN- $\gamma$ ), IL-7 and TNF- $\beta$ ], chemokines [monocyte chemoattractant protein (MCP)-1, MCP-2, MCP-3, monokine induced by IFN- $\gamma$ (MIG) and regulated upon activation, normal T-cell expressed and secreted (RANTES)] and growth factors [growth regulated oncogene (GRO)- $\alpha$, GRO, IL-3, granulocyte-macrophage colony-stimulating factor (GMCSF) and granulocyte colony-stimulating factor (GCSF)] in serum samples taken from patients as described previously (Xu et al. 2004, Fierro et al. 2006). Briefly, the membranes were blocked with a blocking buffer and $1 \mathrm{~mL}$ of a 1:500 dilution of serum from either healthy donors, OHB patients or patients who had recovered from HBV infection was added to the membrane and incubated at room temperature (RT) for $2 \mathrm{~h}$. The membranes were washed and $1 \mathrm{~mL}$ of primary biotin-conjugated antibody was added and incubated at RT for $2 \mathrm{~h}$. The membranes were incubated with $2 \mathrm{~mL}$ of horseradish peroxidase-conjugated streptavidin at RT for $1 \mathrm{~h}$. The membranes were developed by using enhanced chemiluminescence-type solution, were subsequently exposed to film and processed by autoradiography. The densitometry analysis was performed with an Alpha-Innotech FluorChem Imaging System. For each membrane, the individual background value obtained from densitometry values from blank controls included in each assay (Fig. 1A) were subtracted from densitometry values corresponding to each cytokine. Densitometry units corresponding to each cytokine are shown.

Detection of IL-2 production by enzyme linked immunosorbent assay (ELISA) - The Quantikine Human 
IL Immunoassay ELISA test was used to determine the concentration of IL-2. Assays were conducted in triplicate according to the manufacturer's instructions using the serum samples collected from patients and healthy donors (R\&D Systems Minneapolis, MN, USA). The test sensitivity was $7 \mathrm{pg} / \mathrm{mL}$.

Statistical analysis - The data are reported as individual densitometry analyses for each patients or control for each cytokine. The concentration of IL-2 in the serum is reported. The mean for study groups is indicated. The non-parametric Mann-Whitney U test was used to calculate the statistical significance for all assays. A p value of 0.05 was considered significant. Significant $p$ values were corrected by Bonferroni's test to verify that there was indeed a difference between the groups compared.

Ethics - Informed consent was obtained from all participants in the study. The local ethical committee of the Hospital Civil de Guadalajara Fray Antonio Alcalde approved the study protocol (Roman et al. 2010). The protocol was conducted in accordance with the Helsinki Declaration of 1975 as revised in 1983.

\section{RESULTS}

Analysis of pro-inflammatory cytokines in OHBinfected patients suggests a distinct expression profile There were no significant differences between the clinical characteristics of the analysed groups, but was trending toward increased hepatic enzyme levels in OHB-infected individuals (Table). We hypothesised that Nahua OHBinfected patients have differences in anti-inflammatory cytokine secretion levels. Consequently, we tested serum samples from HBV-infected Nahua individuals.

Serum samples from each study group were analysed by dot blot-based assays to detect the relative expression levels of pro-inflammatory cytokines IL-8, TNF- $\alpha$, IL-2, IL-1 and IL-6. The averages determined for each group are shown in Fig. 2. High IL-6 levels are associated with a reduction in HBV replication and IL-1 is important in many inflammatory processes associated with HBV infection, including HCC (Hirankarn et al. 2006, Kuo et al. 2009). However, IL-1 and IL-6 levels were undetectable in the study groups. Interestingly, a significant reduction in IL-8 and TNF- $\alpha$ was observed between both OHB-infected patients and in patients that had resolved HBV infection when comparing to healthy controls (Fig. 2A, B). Serum IL-2 levels were undetectable in the healthy individuals and in patients that had resolved HBV infection. Conversely, a total of $21 \mathrm{OHB}-$ infected patients had significantly increased IL-2 levels (Fig. 2C). These data suggest that IL-2 could be a potential marker to distinguish OHB-infected individuals. Therefore, we compared study groups by a conventional ELISA assay to determine IL-2 concentration in the serum. Serum IL-2 detection was performed in 20 healthy controls, 20 patients that had cleared HBV infection and 21 OHB-infected patients. Healthy controls and patients that had recovered from HBV infection had undetectable IL-2 levels. In contrast, serum IL-2 levels were slightly higher than the lower detection limit in
17 OHB-infected patients ( $8.6 \mathrm{pg} / \mathrm{mL}$ average). Serum samples that had the lowest levels of IL-2 observed by dot blot were undetectable by ELISA (Fig. 2D). This demonstrates that the dynamic range of the dot blotbased assay was greater compared to the ELISA technique. These data support the use of the dot blot assay to evaluate the relative expression level of cytokines IL-2. Moreover, the differential pattern of serum IL-2 concentration between study groups suggests a distinctive cytokine expression in OHB-infected patients.

Increased TGF- $\beta$ levels in OHB-infected patients supports a differential anti-inflammatory process - Our data suggests a difference between the pro-inflammatory profiles of the OHB-infected patients compared to the healthy controls and the patient that had resolved HBV infection (Fig. 2). Subsequently, we investigated whether these differences represented a general mechanism for anti-inflammatory proteins or whether it was specific for pro-inflammatory cytokines. We performed the dot-blot based assay described in Fig. 2 to determine the relative expression levels of IL-13, TGF- $\beta$ and IL-10 in each of the study groups. No significant changes in IL-13 levels were observed between each study group (Fig. 3A). The anti-inflammatory cytokine TGF- $\beta$ was below detectable levels in the serum of healthy controls and there was an increase in TGF- $\beta$ observed in the OHB-infected patients compared to the patients that
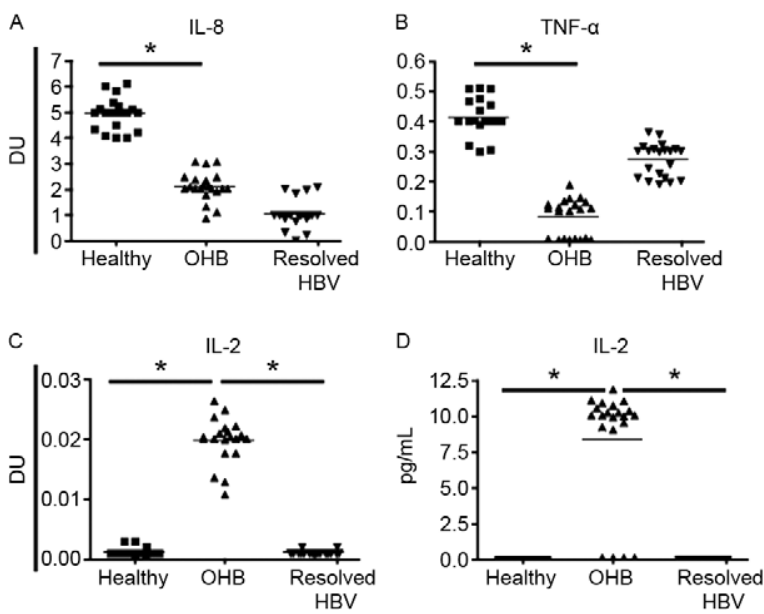

Fig. 1: pro-inflammatory analysis reveals distinct cytokines profiles in occult hepatitis B (OHB) patients. A dot blot assay was used according to the manufacturers' instructions to detect cytokines in serum samples from native Nahua individuals (Ray-Biotech, Norcross, GA, USA). For each membrane, the individual background levels were subtracted. Individual densitometry analyses and averages for each group are showed: interleukin (IL)-8 (A), tumour necrosis factor alpha (TNF- $\alpha$ ) (B) and IL-2 (C). The Quantikine Human IL Immunoassay enzyme linked immunosorbent assay test was used to determine the concentration of IL-2 in sera samples (D). DU: densitometry units; healthy: hepatitis B surface antigen negative (HBsAg-), hepatitis B virus (HBV)DNA and hepatitis B core antibody (anti-HBc-) (n $=20)$; OHB: HBsAg-, HBVDNA and anti-HBc+/- $(\mathrm{n}=21)$; resolved HBV: HBsAg-, HBVDNA and anti-HBc+ $(\mathrm{n}=20)$. A p value of 0.05 was considered significant. 
had recovered from HBV infection (Fig. 3B). A reduction in IL-10 was observed in OHB-infected patients and healthy individuals compared to the patients that had recovered from HBV infection (Fig. 3C). However, these differences were not significant. These results suggest the presence of distinct inflammatory profiles in the OHB-infected patients when compared to patients who had resolved HBV infection.

Distinct IL-15 and IFN- $\gamma$ profiles identified in $\mathrm{OHB}$ infected patients and patients who resolved $H B V$ infection - Based on our data, it is logical to assume that differences would be seen in the immunoregulatory cytokine levels between study groups. We evaluated IL-5, IL-15, IFN- $\gamma$, IL-7 and TNF- $\beta$ levels in the serum following the methods previously described. In all of the groups IL-7 and TNF- $\beta$ levels were below the limit of detection. No differences in IL-5 levels were observed between the study groups (Fig. 4A). Interestingly, IFN- $\gamma$ was undetectable in serum from OHB-infected patients and healthy individuals. In contrast, significant IL-15 and IFN- $\gamma$ levels were observed in patients who had recovered from HBV infection (Fig. 4B, C).

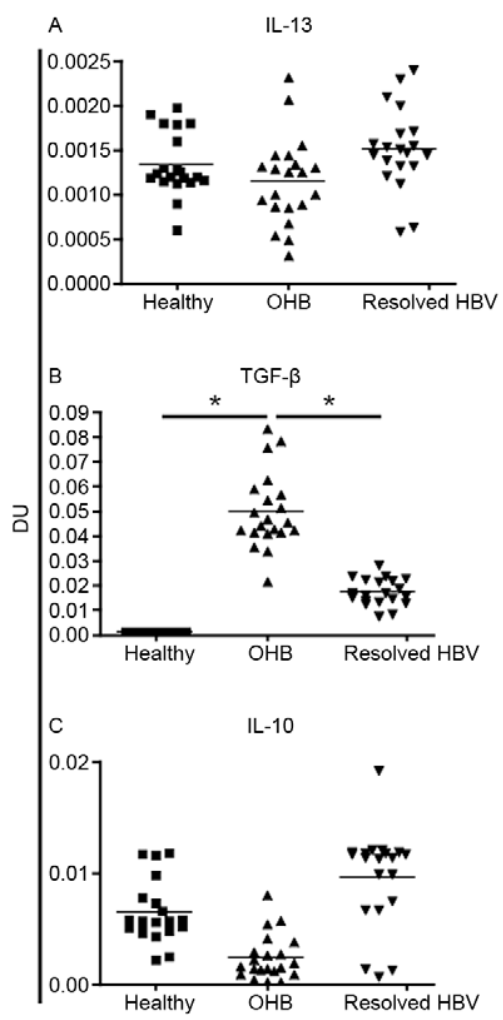

Fig. 2: occult hepatitis $\mathrm{B}(\mathrm{OHB})$ patients have increased tumour growth factor-beta (TGF- $\beta$ ) levels. The cytokines were detected as described in Fig. 1A-C. The individual cytokine levels and average in each group are presented: interleukin (IL)-13 (A), TGF- $\beta$ (B) and IL10 (C). DU: densitometry units; healthy: hepatitis B surface antigen negative (HBsAg-), hepatitis B virus (HBV)DNA and hepatitis B core antibody (anti-HBc-) $(\mathrm{n}=20)$; OHB: HBsAg-, HBVDNA and anti$\mathrm{HBc}+/-(\mathrm{n}=21)$; resolved HBV: HBsAg-, HBVDNA and anti-HBc+ $(n=20)$. A p value of 0.05 was considered significant.
OHB patients secrete chemotactic cytokines - We analysed the chemotactic cytokine expression profiles between each study group. We evaluated the levels of MCP-1, MCP-2, MCP-3, MIG and RANTES in patient serum. The OHB-infected individuals had significantly increased levels of MCP-1 (Fig. 5A) and MCP-2 (Fig. $5 \mathrm{~B})$ compared to the healthy controls and patients that had resolved HBV infection. None of the study groups displayed differences in the level of MCP-3 in the serum (Fig. 5C) and all studied individuals had undetectable levels of MIG. Minimal secretion of RANTES was found in all of the study groups (data not shown). These findings are consistent with the differential cytokines profiles observed in OHB-infected patients.

\section{Expression of growth factors in OHB-infected patients} - To determine the levels of growth factors in the study groups we used dot blot assays to evaluate the serum for GRO- $\alpha$, GRO, IL-3, GMCSF and GCSF. The study groups did not have significant differences of GRO- $\alpha$ (Fig. 6A), GRO (Fig. 6B) and IL-3 levels (Fig. 6C). However, when OHB-infected patients were categorised and analysed by their anti-HBc serologic test, distinct patterns were

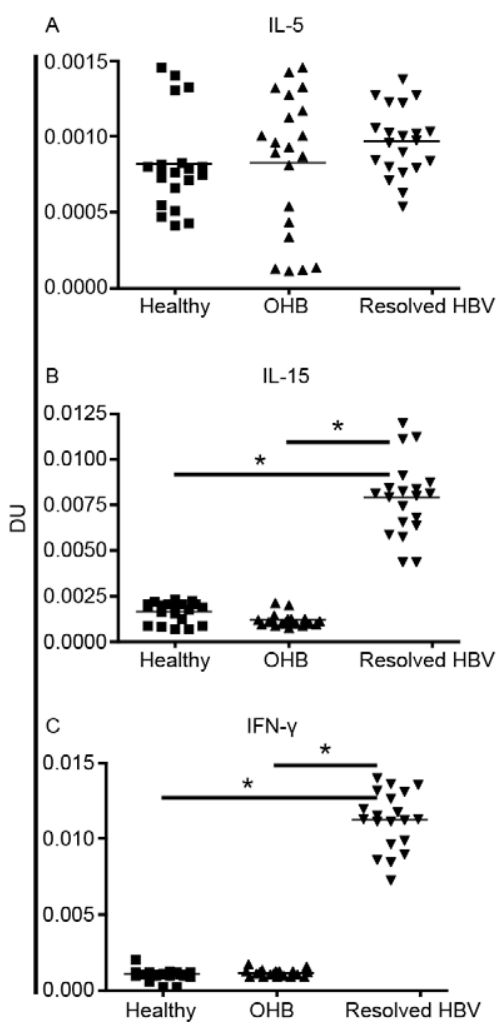

Fig. 3: interferon-gamma (IFN- $\gamma$ ) over-expression in hepatitis B virus (HBV) resolved infection. The cytokines were detected as described in Fig. 1. The individual cytokine levels and average in each group are presented: interleukin (IL)-5 (A), IL-15 (B) and IFN- $\gamma$ (C). DU: densitometry units; healthy: hepatitis B surface antigen negative (HB$\mathrm{sAg}-)$, hepatitis B virus (HBV)DNA and hepatitis B core antibody (anti-HBc-) $(\mathrm{n}=20)$; OHB: HBsAg-, HBVDNA and anti-HBc+/- $(\mathrm{n}=$ 21); resolved HBV: HBsAg-, HBVDNA and anti-HBc+ $(n=20)$. A p value of 0.05 was considered significant. 
seen. Compared to the OHB-infected, anti-HBc- patients $(\mathrm{n}=11)$, the patients that had resolved HBV infection and healthy donors, the OHB-infected, anti-HBc+ patients $(\mathrm{n}=10)$, were seen to have an increased production of GRO- $\alpha$ and IL-3 (data not shown). GMCSF and GCSF levels were below the detection limit for all groups. This data strongly suggests a differential cytokine-dependent mechanism controlling OHB disease development.

\section{DISCUSSION}

This is the first report of a sophisticated modulation of pro and anti-inflammatory molecules, growth factors and chemokines in OHB, genotype-H infected patients (Fig. 1). We investigated a distinctive cytokine profile in OHBinfected patients. As reported by others (Martin et al. 2009), a low detection rate of certain cytokines, including IL-1, IL-6, IL-7, TNF- $\beta$, MIG, GMCSF and GCSF, was also observed in our study. However, even with a reduced percentage of samples testing positive for HBV DNA as a result of the low HBV prevalence in Mexico (Roman et al. 2009), distinct cytokine profiles were seen in OHBinfected patients when compared to healthy individuals and patients that had resolved HBV infection.

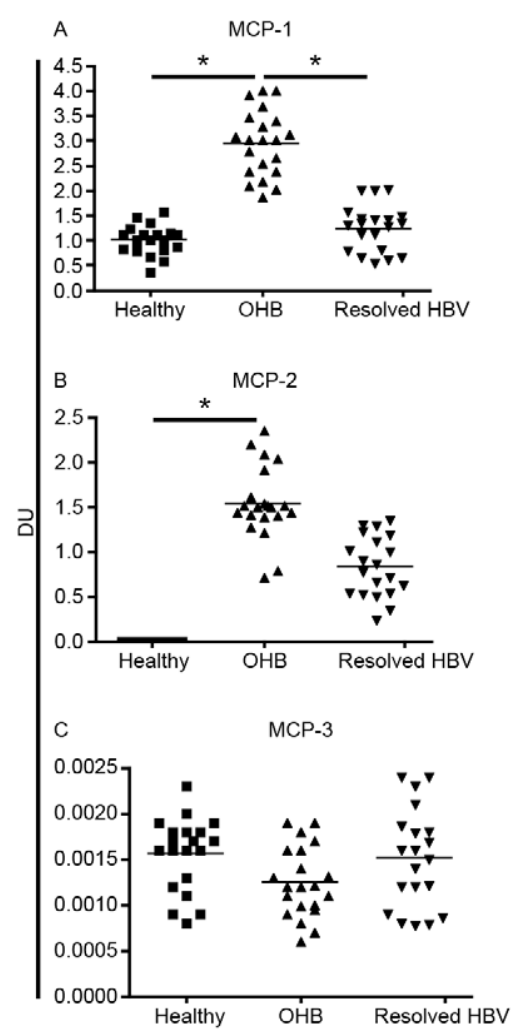

Fig. 4: the chemokine secretion induced by occult hepatitis B (OHB) infection. The cytokines were detected as described in Fig. 1. The individual cytokine levels and average in each group are presented: monocyte chemoattractant protein (MCP)-1 (A), MCP-2 (B) and MCP-3 (C). DU: densitometry units; healthy: hepatitis B surface antigen negative (HBsAg-), hepatitis B virus (HBV)DNA and hepatitis $\mathrm{B}$ core antibody (anti-HBc-) $(\mathrm{n}=20)$; OHB: HBsAg-, HBVDNA and anti-HBc+/- $(\mathrm{n}=21)$; resolved HBV: HBsAg-, HBVDNA and anti$\mathrm{HBc}+(\mathrm{n}=20)$. A p value of 0.05 was considered significant.
Compared to healthy individuals and patients who had recovered from infection, OHB-infected patients had increased TGF- $\beta$ levels in the serum (Fig. 3B). Surprisingly, along with the distinct anti-inflammatory profile observed, an over-expression of IL-2 was exclusively found in OHB-infected patients (Fig. 2C, D), whereas a reduction in pro-inflammatory cytokines, such as IL-8 and TNF- $\alpha$, was observed in OHB-infected patients and those who had resolved HBV infection when compared to healthy individuals (Fig. 2A, B). TGF- $\beta$ modulation in OHB-infected patients is consistent with TGF- $\beta$ involvement in the progression of liver disease (Cheong et al. 2006, Douglas et al. 2010, Li et al. 2010). A decreased ability to produce IL-2 in HBV-infected patients with higher viral loads (Das et al. 2008) and the fact that high concentrations of IL-2 in the serum are related with an early and spontaneous seroconversion and disease resolution (Debnath et al. 2005) support an essential role of IL-2, which we found to be important in OHB-infected patients. Thus, our data suggest that viral transcription repression that results in an HBsAg negative serologic test and undetectable levels of HBV DNA in the serum may be IL-2 modulated in OHB-, genotype-H-infected

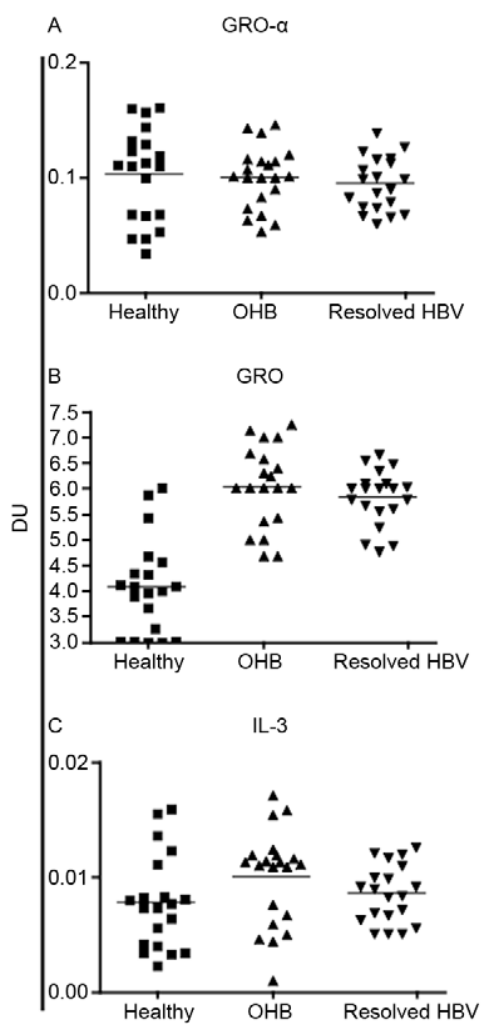

Fig. 5: the differential profiles of growth factors in occult hepatitis B (OHB). The cytokines were detected as described in Fig. 1. The individual cytokine levels and average in each group are presented: growth regulated oncogene (GRO)-alpha (GRO- $\alpha$ ) (A). GRO (B) and interleukin (IL)-3 (C) average levels. DU: densitometry units; healthy: hepatitis B surface antigen negative (HBsAg-), hepatitis B virus (HBV)DNA and hepatitis B core antibody (anti-HBc-) $(n=20)$; OHB: HBsAg-, HBVDNA and anti-HBc+/- $(n=21)$; resolved HBV: HBsAg-, HBVDNA and anti-HBc+ $(n=20)$. A p value of 0.05 was considered significant. 
Nahua patients. However, studies with an increased number of patients should be completed to evaluate this hypothesis. In addition, findings demonstrating that a strong and sustained $\mathrm{CD} 4^{+} \mathrm{T}$ cell-specific $\mathrm{Th} 1$ response during hepatotropic virus infections can result in clearance of viral infection (Corazza et al. 2009) are consistent with our observation of IFN- $\gamma$ over expression patients who resolved HBV infection (Fig. 4C).

Although recent reports have associated OHB infection with HCC development (Chemin et al. 2009, De Mitri et al. 2010), the risk of HBV reactivation in OHB infection is still unclear. We did not find a significant difference in the analysed growth factors in our study groups (Fig. 6). However, increased levels of GRO- $\alpha$ and IL-3 in OHB-infected, anti-HBc+ patients were seen compared to OHB-infected, anti-HBc- patients (data not shown). In addition, a significant increase in MCP-1 and MCP-2 secretion (Fig. 5A, B) and a slight increase in ALT and AST were observed in the OHB-infected individuals (Table). Given that the processes involved in cell differentiation and the progression of hepatic diseases, such as HCC, are modulated through multiple growth factors and chemokines, our preliminary data could suggest that OHB-in-

A

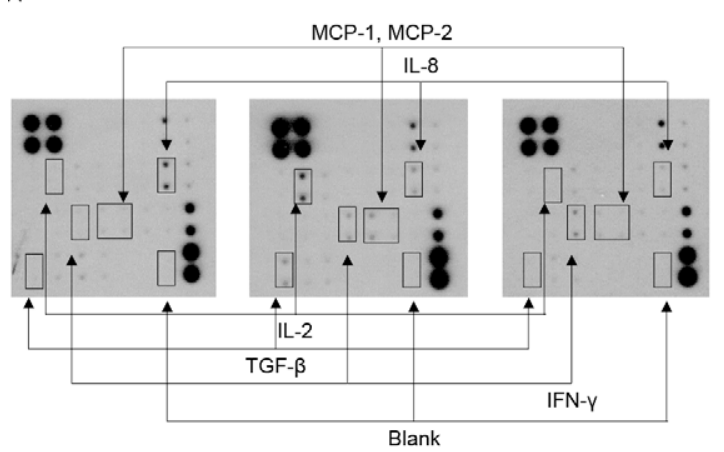

B

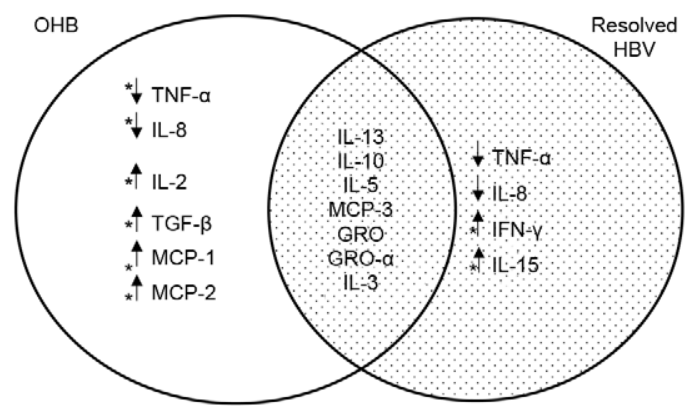

Fig. 6: a complex set of cytokines distinguish occult hepatitis B (OHB) patients from hepatitis $B$ virus (HBV) resolved infection. A: representative dot blots of the study groups are shown (healthy donor: left, OHB-infected patient: middle and patient that resolved HBV: right); B: cytokines that were detected for each group were considered a set and represented as a circle. The intersection of the two sets constitutes the cytokines that were present in comparable quantities. The cytokines in the non-overlapping sections were classified as representative cytokines for each group when their levels were increased or reduced compared with the healthy controls; GRO: growth regulated oncogene; IFN: interferon; IL: interleukin; MCP: monocyte chemoattractant protein; TGF: tumour growth factor; TNF: tumour necrosis factor. Asterisks mean statistical significance. fected, anti-HBc+ patients could have a more severe outcome of infection. However, there are several studies that should be completed to evaluate this hypothesis. Our data suggests that a coordinated cytokine response against HBV infection determines the immune response that develops during $\mathrm{OHB}$ infection, making it potentially plausible to distinguish between OHB-infected patients who have a higher risk to develop liver damage.

In summary, our results highlight differences in cytokine levels in the serum that can distinguishing OHBinfected patients from patients that resolved HBV infection, and these results are consistent with a cytokine involvement during the immune response to viral infection (Chen et al. 2005, Falasca et al. 2006, Basturk et al. 2008, Chan et al. 2008, Larrubia et al. 2009, Macedo et al. 2010). Large-scale studies that involve distinct ethnic groups infected with different HBV genotypes are needed to determine how genetics may influence OHB development. Our data has therapeutic potential for the treatment and diagnosis of hepatic diseases and could lead to new areas of investigation.

\section{ACKNOWLEDGEMENTS}

To Monica Torres and Ansonny Ojeda Duran, for technical help.

\section{REFERENCES}

Akpolat N, Yahsi S, Godekmerdan A, Demirbag K, Yalniz M 2005. Relationship between serum cytokine levels and histopathological changes of liver in patients with hepatitis B. World J Gastroenterol 11: 3260-3263.

Basturk B, Karasu Z, Kilic M, Ulukaya S, Boyacioglu S, Oral B 2008. Association of TNF-alpha-308 polymorphism with the outcome of hepatitis B virus infection in Turkey. Infect Genet Evol 8: 20-25.

Campos RH, Mbayed VA, Pineiro YL 2005. Molecular epidemiology of hepatitis B virus in Latin America. J Clin Virol (Suppl. 2) $34: \mathrm{S} 8-13$.

Candotti D, Allain JP 2009. Transfusion-transmitted hepatitis B virus infection. J Hepatol 51: 798-809.

Chan HL, Tse AM, Chim AM, Wong VW, Choi PC, Yu J, Zhang M, Sung JJ 2008. Association of cytokine gene polymorphisms and liver fibrosis in chronic hepatitis B. J Gastroenterol Hepatol 23: 783-789.

Chemin I, Guillaud O, Queyron PC, Trepo C 2009. Close monitoring of serum HBV DNA levels and liver enzymes levels is most useful in the management of patients with occult HBV infection. J Hepatol 51: 824-825.

Chen CC, Yang SY, Liu CJ, Lin CL, Liaw YF, Lin SM, Lee SD, Chen PJ, Chen CJ, Yu MW 2005. Association of cytokine and DNA repair gene polymorphisms with hepatitis B-related hepatocellular carcinoma. Int J Epidemiol 34: 1310-1318.

Cheong JY, Cho SW, Hwang IL, Yoon SK, Lee JH, Park CS, Lee JE, Hahm KB, Kim JH 2006. Association between chronic hepatitis B virus infection and interleukin-10, tumor necrosis factor-alpha gene promoter polymorphisms. J Gastroenterol Hepatol 21: 1163-1169.

Corazza N, Badmann A, Lauer C 2009. Immune cell-mediated liver injury. Semin Immunopathol 31: 267-267.

Das A, Hoare M, Davies N, Lopes AR, Dunn C, Kennedy PT, Alexander G, Finney H, Lawson A, Plunkett FJ, Bertoletti A, Akbar AN, Maini MK 2008. Functional skewing of the global CD8 T cell population in chronic hepatitis B virus infection. $J$ Exp Med 205: 2111-2124. 
De Mitri MS, Cassini R, Bernardi M 2010. Hepatitis B virus-related hepatocarcinogenesis: molecular oncogenic potential of clear or occult infections. Eur J Cancer 46: 2178-2186.

Debnath CR, Alam K, Sarker CB, Rahman S, Ahmad N, Rahman S, Khan GK, Sutradhar SR, Miah MT 2005. Serum IL-2 in chronic hepatitis B virus infected patients and its association with disease activity. Mymensingh Med J 14: 125-127.

Douglas DB, Beiting DP, Loftus JP, Appleton JA, Bliss SK 2010. Combinatorial effects of interleukin 10 and interleukin 4 determine the progression of hepatic inflammation following murine enteric parasitic infection. Hepatology 51: 2162-2171.

Falasca K, Ucciferri C, Dalessandro M, Zingariello P, Mancino P, Petrarca C, Pizzigallo E, Conti P, Vecchiet J 2006. Cytokine patterns correlate with liver damage in patients with chronic hepatitis B and C. Ann Clin Lab Sci 36: 144-150.

Fierro NA, Pedraza-Alva G, Rosenstein Y 2006. TCR-dependent cell response is modulated by the timing of CD43 engagement. $J$ Immunol 176: 7346-7353.

Frodsham AJ, Zhang L, Dumpis U, Taib NA, Best S, Durham A, Hennig BJ, Hellier S, Knapp S, Wright M, Chiaramonte M, Bell JI, Graves M, Whittle HC, Thomas HC, Thursz MR, Hill AV 2006. Class II cytokine receptor gene cluster is a major locus for hepatitis B persistence. Proc Natl Acad Sci 103: 9148-9153.

Hirankarn N, Kimkong I, Kummee P, Tangkijvanich P, Poovorawan Y 2006. Interleukin-1 beta gene polymorphism associated with hepatocellular carcinoma in hepatitis B virus infection. World $J$ Gastroenterol 12: 776-779.

Hollinger FB, Sood G 2010. Occult hepatitis B virus infection: a covert operation. $J$ Viral Hepat 17: 1-15.

Kuo TM, Hu CP, Chen YL, Hong MH, Jeng KS, Liang CC, Chen ML, Chang C 2009. HBV replication is significantly reduced by IL-6. J Biomed Sci 16: 41-49.

Kurbanov F, Tanaka Y, Mizokami M 2010. Geographical and genetic diversity of the human hepatitis B virus. Hepatol Res 40: 14-30.

Larrubia JR, Benito-Martinez S, Miquel-Plaza J, Sanz-de-Villalobos E, Gonzalez-Mateos F, Parra T 2009. Cytokines - their pathogenic and therapeutic role in chronic viral hepatitis. Rev Esp Enferm Dig 101: 343-351.

Li J, Wu W, Peng G, Chen F, Bai M, Zheng M, Chen Z 2010. HBcAg induces interleukin-10 production, inhibiting $\mathrm{HBcAg}$-specific Th17 responses in chronic hepatitis B patients. Immunol Cell Biol 88: 834-841.

Macedo LC, Isolani AP, Visentainer JE, Moliterno RA 2010. Association of cytokine genetic polymorphisms with the humoral immune response to recombinant vaccine against $\mathrm{HBV}$ in infants. J Med Virol 82: 929-933.

Martin CM, Welge JA, Shire NJ, Shata MT, Sherman KE, Blackard JT 2009. Cytokine expression during chronic versus occult hepatitis B virus infection in HIV co-infected individuals. $C y$ tokine 47: 194-198.

Mbayed VA, Pineiro y Leone FG, Pezzano SC, Campos RH 2009. Molecular characterization of hepatitis B virus genotype A from Argentina and Brazil. Arch Virol 154: 525-529.

Osiowy C, Giles E, Tanaka Y, Mizokami M, Minuk GY 2006. Molecular evolution of hepatitis B virus over 25 years. $J$ Virol 80 : 10307-10314.

Prieto M 2009. Antibody to hepatitis B core antigen-positive grafts: not perfect but no longer marginal. Liver Transpl 15: 1164-1168.

Racanelli V, Rehermann B 2006. The liver as an immunological organ. Hepatology 43 (Suppl. 1): S54-S62.

Raimondo G, Allain JP, Brunetto MR, Buendia MA, Chen DS, Colombo M, Craxi A, Donato F, Ferrari C, Gaeta GB, Gerlich WH, Levrero M, Locarnini S, Michalak T, Mondelli MU, Pawlotsky JM, Pollicino T, Prati D, Puoti M, Samuel D, Shouval D, Smedile A, Squadrito G, Trepo C, Villa E, Will H, Zanetti AR, Zoulim F 2008. Statements from the Taormina expert meeting on occult hepatitis B virus infection. J Hepatol 49: 652-657.

Raimondo G, Pollicino T, Romano L, Zanetti AR 2010. A 2010 update on occult hepatitis B infection. Pathol Biol (Paris) 58: 254-257.

Roman S, Panduro A, Aguilar-Gutierrez Y, Maldonado M, VazquezVandyck M, Martinez-Lopez E, Ruiz-Madrigal B, Hernandez-Nazara Z 2009. A low steady HBsAg seroprevalence is associated with a low incidence of HBV-related liver cirrhosis and hepatocellular carcinoma in Mexico: a systematic review. Hepatol Int 3: 343-355.

Roman S, Tanaka Y, Khan A, Kurbanov F, Kato H, Mizokami M, Panduro A 2010. Occult hepatitis B in the genotype H-infected Nahuas and Huichol native Mexican population. J Med Virol 82: $1527-1536$.

Sanchez LV, Maldonado M, Bastidas-Ramirez BE, Norder H, Panduro A 2002. Genotypes and S-gene variability of Mexican hepatitis B virus strains. J Med Virol 68: 24-32.

Sanchez LV, Tanaka Y, Maldonado M, Mizokami M, Panduro A 2007. Difference of hepatitis B virus genotype distribution in two groups of Mexican patients with different risk factors. High prevalence of genotype $\mathrm{H}$ and $\mathrm{G}$. Intervirology 50: 9-15.

Torres-Baranda R, Bastidas-Ramirez BE, Maldonado-Gonzalez M, Sanchez-Orozco LV, Vazquez-Vals E, Rodriguez-Noriega E, Panduro A 2006. Occult hepatitis B in Mexican patients with $\mathrm{HIV}$, an analysis using nested polymerase chain reaction. Ann Hepatol 5: 34-40.

Wang FS, Zhang Z 2009. Host immunity influences disease progression and antiviral efficacy in humans infected with hepatitis B virus. Expert Rev Gastroenterol Hepatol 3: 499-512.

Xu Y, Kulkosky J, Acheampong E, Nunnari G, Sullivan J, Pomerantz RJ 2004. HIV-1-mediated apoptosis of neuronal cells: proximal molecular mechanisms of HIV-1-induced encephalopathy. PNAS 101: 7070-7075. 